\title{
Complementarity of the Relational Network Theory and Conceptual Blending
}

Ke y w o r d s : Relational Network Theory; Conceptual Blending; Conceptual Integration Theory; mental spaces; linguistic network; meaning construction

Słowa klucze: Teoria Sieci Relacyjnych; Teoria Amalgamatów; Teoria Integracji Konceptualnej; przestrzenie mentalne; sieć językowa; konstruowanie znaczenia

\section{Introduction}

Intrinsic to human communication, language has always been a meticulously studied phenomenon. Over the decades, linguists have been trying to find the answer to the most perplexing questions concerning its internal and external structure and the hidden aspects of the meaning construction process. Although there is an abundance of research into this human-specific means of communication, there is no unified theory of language. Cognitive Linguistics itself, as emphasised by Geeraerts and Cucykens (2007: 3-4), "constitutes a cluster of many partially overlapping approaches rather than a single well-defined theory." Hence, there does seem to be a need for finding a link bridging the gap between various linguistic studies. Only when researchers start looking for a unified approach to the study of language, will 
they be able to unravel the intricacies of linguistic and cognitive operations. All they need is a cornerstone that they could base their studies on and conduct their own scientific research. What is more, linguists should draw upon neuroscientific findings and explain language-related phenomena by referring to the structure and workings of the human brain, which is emphasised by Pulvermüller (1999: 272) who underlines that "[a] language theory at the neuronal level is required in cognitive neuroscience."

Sydney Lamb (1999) made such an attempt to translate his theory into neurobiological terms. He developed the Relational Network Theory (henceforth RNT), which draws extensively upon stratificational grammar and is anchored in neuroscientific discoveries. Lamb's theory may thus appear to be a real breakthrough in linguistic research as it is consistent with recent findings in the field of neuroscience. Therefore it seems reasonable to compare its assumptions with other linguistic theories as it may shed some new light upon language-related processes. The aim of the paper is to show that, though divergent on the surface, Lamb's Relational Network Theory (Lamb 1999) is compatible with Fauconnier and Turner's Conceptual Integration Theory, a.k.a. Conceptual Blending (Fauconnier and Turner 1998), and that they may complement each other in the elucidation of linguistic operations. First, major tenets of the stratified approach to language will be described. Subsequently, a brief outline of Fauconnier and Turner's theory will be given and their integration network providing an insight into cognitive operations will be presented. Finally, it will be shown that the RNT chime in with cognitive approaches to language, and that the two theories, i.e. Fauconnier and Turner's Conceptual Integration Theory (CNT in short) and Lamb's RNT are complementary and may act in accord in the examination of various linguistic processes.

\section{Stratificational Grammar and the Relational Network Theory}

According to the stratificational approach, language is an intermediary between so-called phonic correlations, which establish correspondences between articulatory or auditory representations of linguistic elements, and conceptual correlations (Lockwood 1972). As a stratified system of relations (Lamb 1966), language enables its users to encode and decode messages, or in other words, to articulate thoughts and to comprehend spoken words 
(Fig. 1). Typically, language exhibits four main strata, i.e. phonemic, morphemic, lexemic and sememic. However, there are some languages, such as English, which feature additional two polar levels called hypophonemic (or phonetic) and hypersememic, a.k.a. gnostemic or semantic (Lamb 1966: 18). The hypohphonemic stratum specifies how phonological components are arranged in segments and clusters. Contrary to the phonemic level, it takes, however, into account the fact that "segment and cluster phenomena can transcend syllable boundaries (Lockwood 1972: 225)," and therefore is regarded as an immediate stage between "linguistic structure and its external manifestation, articulatory, acoustic, and auditory (Lamb 1966: 29)." The hypersememic level is, in turn, related to the organisation of knowledge and viewed as "a sort of middle ground between language and non-language (Lockwood 1972: 165)." Lockwood (1972: 165) underlines that "the gnostemic stratal system, being the closest to the conceptual correlations, represents as nearly as possible the natural way of thinking about things, while the sememic provides the first degree of accommodation of this to what will ultimately emerge as speech or writing."

Figure 1. Linguistic stratal system

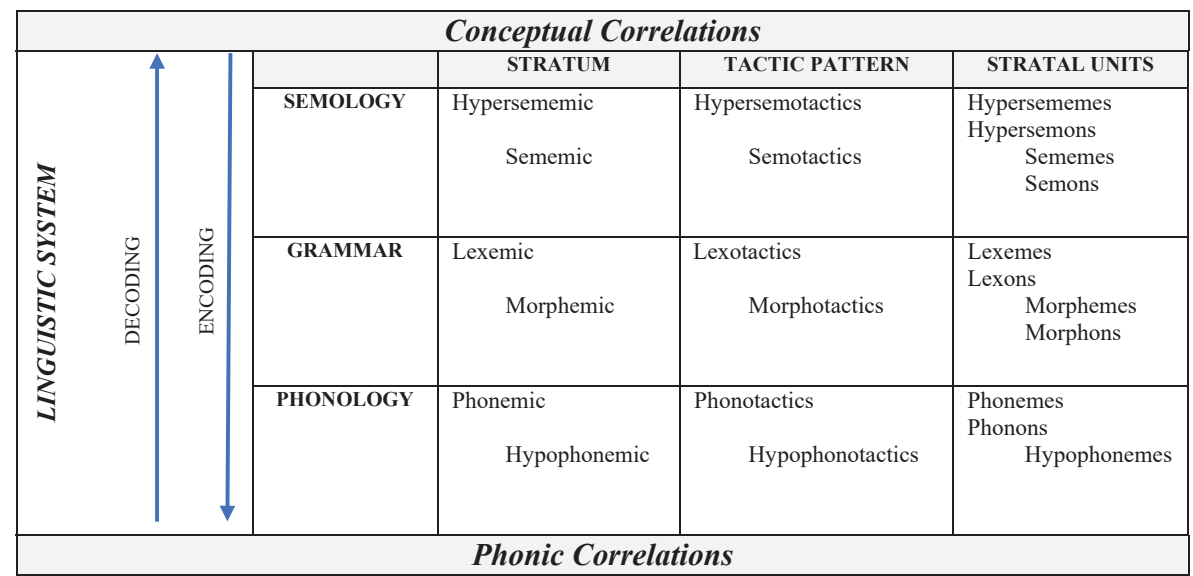

Source: own representation based on Lamb 1966 and Lockwood 1972.

Important as it is, each stratum inheres a different number of elements. Phonological stratum incorporates the smallest number of units, contrary to 
the highest layer which abounds in multifarious components. Apart from the phonological stratum, linguistic levels are extendable and modifiable, and the number of their elements may increase due to inexorable language change and the influx of new words. Significantly, elements at each stratum are subject to tactic patterns, i.e. rules which determine how elements of a given linguistic level may be combined. Lockwood (1972: 7) compares the tactics to the traditional syntax and adds that "instead of there being one tactics for the whole language, a separate tactics is believed to exist on each stratum." As a result, the following tactic patterns may be distinguished: phonotactics, morphotactics, lexotactics, semotactics, as well as hypersemotactics and hypophonotactics. Each tactic pattern is connected to a higher stratum by means of the alternation pattern, which controls the transition of elements between neighbouring strata.

Structural layers comprise two types of units: those ending with the suffix -on (eg. phonon, morphon, lexon), which, as Lamb (2004: 381) emphasises, are "the points in the system from which connections extend to the next lower stratum," and those which are composed of the already-mentioned -on elements and have the suffix -eme (eg. phoneme, morpheme, lexeme), and represent those elements that connect with the higher stratum and the tactics of a given level. For instance, the phoneme ${ }^{\mathrm{P}} / \mathrm{t} /$ is composed of the phonons ${ }^{\mathrm{PN}} / \mathrm{Ap} /$ apical, ${ }^{\mathrm{PN}} / \mathrm{Cl} /$ closed and ${ }^{\mathrm{PN}} / \mathrm{Uv} /$ unvoiced (Lamb 1999: 25); the lexeme L/undergo/ is composed of lexons ${ }^{\mathrm{LN}} /$ under/ and $\mathrm{LN} / \mathrm{go} /$; and the sememe $\mathrm{S} /$ horse/ comprises the semon $\mathrm{SN} /$ mare/ (Lockwood 1972).

Lockwood (1972: 26) emphasises that all the units of the network, i.e. the -eme and -on elements, e.g. phonemes/phonons, lexemes/lexons, etc., are merely points in the total network of relationships because it is at this convergence points that the meaning arises. He uses the term 'entities' to refer to the aforementioned -eme and -on elements and emphasises that "these labels are simply added at various points in the total network of relationships as reference points to aid the linguist in discussing this system (Lockwood 1972: 26)" because what really matters is the network of relationships which the linguistic elements constitute. Lockwood (1972: 26) also adds that " $[\mathrm{t}] \mathrm{he}$ only 'entities', which are not just points in the linguistic network are the conceptual and phonic correlations, which connect to the linguistic system but lie outside it." (Fig. 1) 
The stratal system of relations features four types of patterns, which are responsible for sustaining proper intra- and inter-stratal connections between linguistic elements (Lamb 1966). Apart from the aforementioned tactic and alternation patterns intrinsic to each linguistic level, there is also a sign pattern and a knot pattern, which "ties" together the alteration, sign and tactic pattern and joins two adjacent strata. The sign pattern is a graphic notation system used in stratificational linguistics. It comprises a system of lines that stand for connections between linguistic elements and nodes, which are convergence points where lines intersect, merge and split. Importantly, nodes themselves do not contain any information because, as Lamb (1999) emphasises, meaning is in the connectivity, and the function of a node is to integrate all the information which is crucial to represent the meaning, function or the form of a given linguistic element. He avers that upward orientation is towards meaning or function of a linguistic unit, whereas downward towards expression.

Lamb (1966) distinguishes two basic types of nodes AND and OR, which show the relation of a composite node to its components (Fig. 2). The AND node is represented in the graphic notation system as a triangle or its upside-down equivalent and shows that both elements need to be taken into account for the upper or lower node to be meaningful. The OR node, on the other hand, allows for the alternative combination of the activation flow amongst the interlinked elements and is represented graphically as either an under or over square bracket. Additionally, nodes may exhibit DOWNWARD (a triangle and an over square bracket) or UPWARD (an upside-down triangle and an under bracket) orientation, and ORDERED or UNORDERED arrangement of realizational lines attached to the node, which is shown in the graphic notation system, respectively, as two or more lines coming from different points or just from one. Significantly, "impulses are allowed to move along the lines, in either direction [they] move downward during the production process and upward during the decoding process (Lamb 1966: 10)." 
Figure 2. Fundamental types of nodes used in stratificational linguistics

\begin{tabular}{|c|c|c|c|c|}
\hline & \multicolumn{2}{|c|}{ UNORDERED } & \multicolumn{2}{|c|}{ ORDERED } \\
\hline & AND & OR & AND & OR \\
\hline \multirow[t]{2}{*}{ DOWNWAR } & & & & \\
\hline & $\begin{array}{l}\text { Downward activation from } \mathbf{z} \\
\text { leads down to } \mathbf{x} \text { and simul- } \\
\text { taneously to } \mathbf{y} \text {. } \\
\text { Upward activation from } \mathbf{x} \\
\text { and } \mathbf{y} \text { goes to } \mathbf{z} \text {. }\end{array}$ & $\begin{array}{l}\text { Downward activation } \\
\text { from } \mathbf{z} \text { leads down to } \mathbf{x} \\
\text { and }[\mathrm{sic}] \mathbf{y} \text {. } \\
\text { Upward activation from } \\
\mathbf{x} \text { or } \mathbf{y} \text { goes up to } \mathbf{z} \text {. }\end{array}$ & $\begin{array}{l}\text { Downward activation from } \\
\mathbf{z} \text { leads down to } \mathbf{x} \text { and later } \\
\text { to } \mathbf{y} \text {. } \\
\text { Upward activation from } \mathbf{x} \\
\text { and later from } \mathbf{y} \text { goes to } \mathbf{z} \text {. }\end{array}$ & $\begin{array}{l}\text { Downward activation } \\
\text { from } \mathbf{z} \text { leads down to } \mathbf{x} \\
\text { if possible, otherwise to } \\
\mathbf{y} \text {. Upward activation } \\
\text { from } \mathbf{x} \text { or } \mathbf{y} \text { goes up to } \\
\mathbf{z} \text {. }\end{array}$ \\
\hline \multirow[t]{2}{*}{ UPWARD } & & & & \\
\hline & $\begin{array}{l}\text { Upward activation from } \mathbf{z} \\
\text { goes up to } \mathbf{x} \text { and } \mathbf{y} \text {. } \\
\text { Downward activation from } \mathbf{x} \\
\text { and } \mathbf{y} \text { leads down to } \mathbf{z} \text {. }\end{array}$ & $\begin{array}{l}\text { Upward activation from } \\
\mathbf{z} \text { goes up to } \mathbf{x} \text { and } \mathbf{y} \text {. } \\
\text { Downward activation } \\
\text { from } \mathbf{x} \text { or } \mathbf{y} \text { leads down } \\
\text { to } \mathbf{z}\end{array}$ & $\begin{array}{l}\text { Upward activation from } \mathbf{z} \\
\text { goes up to } \mathbf{x} \text { and later to } \mathbf{y} \text {. } \\
\text { Downward activation from } \\
\mathbf{x} \text { and later from } \mathbf{y} \text { leads } \\
\text { down to } \mathbf{z} \text {. }\end{array}$ & $\begin{array}{l}\text { Upward activation from } \\
\mathbf{z} \text { goes up to } \mathbf{x} \text { if possi- } \\
\text { ble, otherwise to } \mathbf{y} \text {. } \\
\text { Downward activation } \\
\text { from } \mathbf{x} \text { or } \mathbf{y} \text { goes down } \\
\text { to } \mathbf{z} \text {. }\end{array}$ \\
\hline
\end{tabular}

Source: own representation based on Lamb 1966: 9, 1999: 67.

As mentioned previously, in stratificational grammar, language is viewed as a network of relationships extended over various structural layers, and the meaning of a linguistic element is in the connectivity and depends upon other interrelated nodes which show its meaning, function, or form, or its relation to other linguistic units. Linguistic system, being a well-organised network, the recruitment of one node triggers the activation of other adjoined or interconnected nodes, and meaning construction process revolves around node recruitment and connection building. For instance, the English lexeme $\mathrm{L} /$ trash- $^{-}$ can/ activates two lexons ${ }^{\mathrm{LN}} / \mathrm{trash} /$ and $\mathrm{LN} / \mathrm{can} /$. The relationship between these elements is the DOWNWARD ORDERED AND, which is graphically represented by a triangular node with an upward line directed toward the semological level and downward lines stemming from the bottom of the triangle (Fig. 3). The downward lines impose a left to right ordering of the elements and point towards the form of the linguistic unit. 
Figure 3. The relational subnetwork for a lexeme/trashcan/

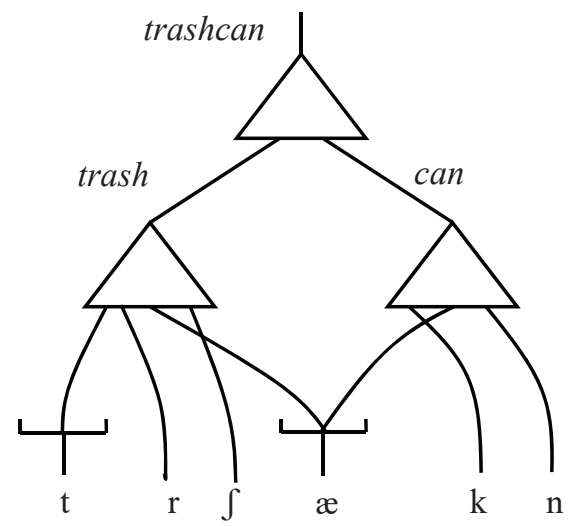

Source: own representation.

For meaning construction process to occur, structural layers need to interact with each other, and the relationship between the elements of adjacent strata is called realization (Lockwood 1972: 27). Realizational relations specify vertical connections between lower and upper elements, whereas tactical ones, imposed by tactic patterns, determine the horizontal arrangement of elements within a single stratum. There are various types of realizational relationships, such as composite realisation, alternation, empty realisation, neutralisation or diversification. An example of diversification is the English lexeme ${ }^{\mathrm{L}} / \mathrm{go} /$ which is "realised by ${ }^{\mathrm{LN}} / \mathrm{go} /$, which in turn is realised by the morpheme $\mathrm{M} / \mathrm{go} /$ in some environments and by the morpheme $\mathrm{M} / \mathrm{wen} /$ in others (Lockwood 1972: 27)."

Apart from nodes, which are the main building blocks of the relational network, Lamb (1999) distinguishes nections which incorporate nodes together with their internal lines, i.e. lines which join two nodes, the lower of which connects toward expression and the upper toward meaning or function (Lamb 1999: 73). Such nections are believed to be represented biologically as a cortical column comprising approximately a hundred neurons, and a node is said to correspond to a 'bundle' of neurons (Lamb 1996, 1999). 
Figure 4. A nection

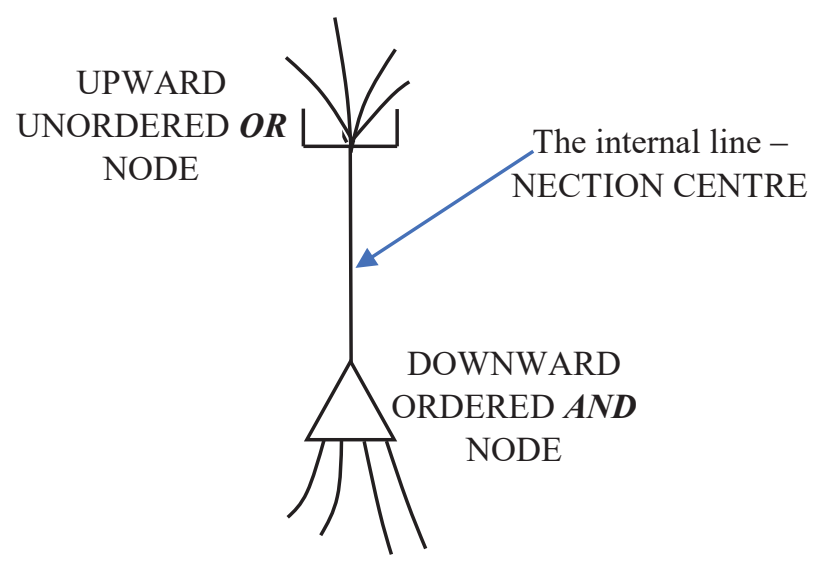

Source: own representation based on Lamb 1999: 73.

Significant as it is, neurons and nections share a number of similarities. Not only do their structures bear a close resemblance (Fig. 4) but they also function in a comparable way. For instance, the transmission of information across the cortex requires the activation of intermediary neuronal clusters. The RNT, likewise, allows only for a successive transition between different linguistic strata. Nodes at the semantic level do not have direct connections with nodes on the phonemic stratum, and the intermediary lexical and morphological nodes need to be triggered for the phonemic representation of a given element to be evoked. What is more, nodes sustain connections with other interrelated nodes even over long distances and a single node may belong to various relational subnetworks. Similarly, a single neuron may be adopted by several different functionally-coupled neuronal ensembles (Abeles 1991), and its apical dendrites may extend towards neurons placed in distant areas of the cortex. The ignition of one neuron does not, however, guarantee the activation of the entire web. For the assembly to ignite, a sufficiently large number of neurons must be triggered. Their frequent activation contributes to the strengthening of synaptic connections and to the loosening of links with neurons outside a given assembly. Pulvermüller (1999: 260) emphasises that "[1]ater on, the strong connections within the higher-order assembly guarantee ignition of the entire assembly when part of it is being 
activated and, thus, they guarantee a high correlation of activity of all cell assembly parts, and, consequently, the endurance of the assembly."

In a similar vein, cross-node links get strengthened when frequently activated, or wither away if they are not recruited sufficiently often. New connections may also be created and they are established in accordance with a well-known Hebbian principle, which for the purpose of the RNT could be rewritten as follows: "nodes that fire together, wire together." Similarly to neurons, nodes are affected by excitatory or inhibitory impulses, and when the action potential of a node exceeds the threshold value, an impulse is transmitted to interconnected nodes. A threshold of a node is a variable which plays a significant role because, as Lamb (1999: 179) highlights, "a part of the learning process has to consist of adjustments in the threshold so that the node will be neither too easily satisfied nor too stringent in its demands".

Congruent with neurobiological studies, the RNT shows that words are represented in the brain as relational subnetworks combining nodes spread over divergent modalities. The central coordinating nection for a given concept integrates all the nodes which designate all its features and those which reflect experiential imprints created as a result of past interactions. Thus, a simple concept CAT, along with the lexemic form of the word, triggers the activation of nections in the visual, auditory and somatosensory modality, and ignites nections for other phonemically or semantically related concepts. In neurobiological terms, the concept for the CAT is believed to evoke nodes within the perisylvian cortice, which houses the core language areas, and in other areas of the brain so as to reflect sensory, motor or emotional experiences associated with a given concept. Even the most recent studies concerning semantic representation confirm that "conceptual knowledge is a widely distributed neural network (Patterson et al. 2007: 976)" and that concept retrieval involves "multimodal integration of sensory-motor features" associated with a word (Fernandino et al. 2016: 2021). Additionally, scientists distinguish so-called 'semantic hubs' which integrate features of a concept from spatially distributed brain areas (Patterson et al. 2007; Westerland, Pylkkänen 2017), and which are likely to be akin to Lamb's coordinating nections.

Lamb's RNT appears to provide a very comprehensive picture of the linguistic system. Not only does it show a cross-section through the entire linguistic system (Fig. 5), but also draws on neurobiological studies to support its assumptions. Thus, it seems to pose a valuable launching pad from which 
linguistic system may be further scrutinised. By contrast, Fauconnier and Turner's CIT zooms in on that part of the linguistic system which is essential to be brought to light for meaning construction process to follow. It illuminates only the blending process and disregards other relationships between linguistic elements which are also crucial for linguistic processing. However, since the two theories view language from a different perspective, they may be rendered complementary and they both may contribute significantly to the elucidation of language-related processes. Before the above hypothesis is presented in greater detail, a brief outline of the CIT will be provided.

Figure 5. The lexeme $\mathrm{L} / \mathrm{cat} /$ and part of its subnetwork

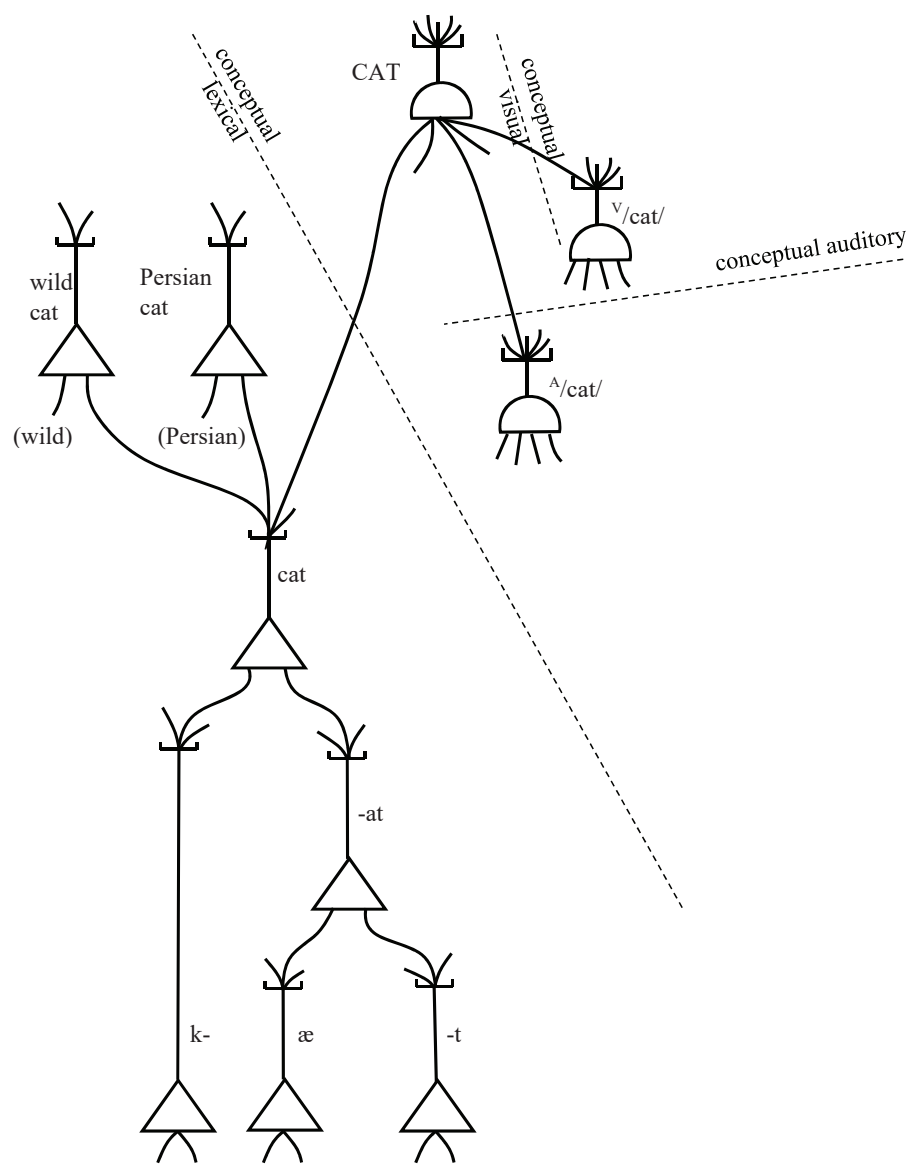

Source: own representation based on Lamb 1999: 76. 


\section{Conceptual Integration Theory}

According to Fauconnier (1994, 1997), language comprehension and production involves the division of ongoing linguistic discourse into cohesive conceptual packets, otherwise referred to as mental spaces. As thought and discourse unfold, mental spaces proliferate and are structured in a neatly organised array. Important as it is, they are always established relative to the already-evoked structures and retain vital cross-space connections with related space elements ensconced in other spaces, which enables the transfer of relevant information and crucial inferences across the lattice constituents.

Built up for purposes of local understanding, mental spaces draw upon repositories of long-term memory and its more stable knowledge structures, such as domains. A single mental space may be profiled against more than one conceptual domain if need be but it always inheres elements and relations specified by linguistic input. The internal structure of a mental space is framed in accordance with background knowledge as linguistic input "triggers a search through a long-term memory for a frame that will anchor the message-level representation (Coulson 2001: 37)." Though created on-line, those conceptual packets are fairly ordered structures because their internal organisation is influenced by a frame extracted from long-term memory. Such pre-stored knowledge structures determine the fine-grained partitioning of the linguistic input into coherent conceptual packets and facilitate the establishment of relations between space elements. Significantly, once activated, mental spaces may be easily re-accessed, modified or supplied with additional information, which may result in the semantic reanalysis of the frame applicable to a given mental space, as it is the case in, for instance, joke-comprehension (Couslon 2001).

It is worth emphasising that the internal structure of a mental space may not only be modified but even blended. Regarded as the extension of the Mental Space Theory, the Conceptual Integration Theory illuminates the amalgamation of space structures into one conceptual packet. Fauconnier and Turner (1998) set forth a four-space model that is constrained by background knowledge and so-called optimality principles which are to secure the proper transfer of structures across spaces. Briefly speaking, a typical integration network incorporates two input spaces, a.k.a. a target and a source space, a blended space which is the hub of the entire configuration, and a ge- 
neric space which permeates the entire network and represents background knowledge evoked from long-term memory to guide and restrain the meaning construction process (Fig. 6). This generic space enables the transfer of structures across spaces and facilitates mappings across space elements. Significantly, not all information included in the input spaces is transferred to the blended space as its internal organisation is restricted by the generic space and so-called optimality constraints and optimality pressures (Fauconnier and Turner 2002: 329).

Figure 6. Conceptual Integration Network

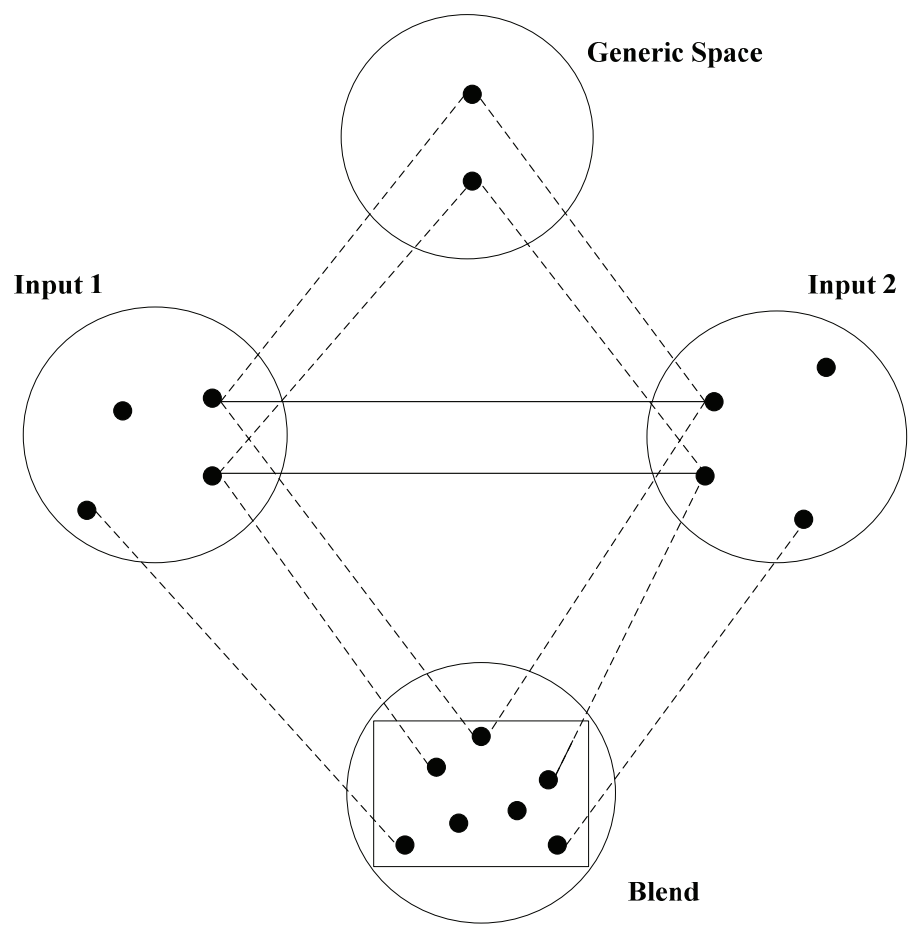

Source: own representation adapted from Fauconnier 1997: 151. 


\section{Relational Network Theory and Conceptual Network Theory}

Though on the surface, the RNT differs significantly from the CNT, it may, in fact, feed the mental binding process by providing valuable insight into the linguistic network. The CIT deals mainly with the semantic level of language, whereas the RNT shows various linguistic strata, and integration appears to be one of the operations determining the relation between interand intrastratal elements. The RNT appears to reveal the hidden layers of linguistic processing which may be useful in the analysis of such phenomena as slips of the tongue. The Mental Space Grammar, and the CIT likewise, focus mainly on space elements and their connections only within the evoked lattice. In contrast, the RNT takes into account lower levels of language which are disregarded in the CNT and highlights that " $[\mathrm{t}]$ he linguistic system is not a single system but an interconnected group of different subsystems (Lamb 1999: 49)." In Lamb's theory, these are relations which are of primary importance as they lie at the core of the meaning construction process. As an example, consider a sentence provided by Sydney Lamb (1999: 199):

\section{Princess is eating a goldfish.}

(where Princess is the name of a cat)

According to the Mental Space Theory (Fauconnier 1994), the sentence evokes a mental space $\mathrm{M}$, which is structured by a frame in which the verb EAT imposes semantic relations upon space elements. The mental space M is profiled against the reality space $\mathrm{R}$, with which it retains vital connections. Owing to the so-called Access Principle, "an expression that names and describes an element in one mental space can be used to access a counterpart of that element in another mental space (Faucconnier 1997: 41)." In consequence, it becomes clear that Princess from the space $M$ identifies the cat from the reality space. In accordance with the Mental Space Theory, the induced space configuration may be presented as follows (Fig. 7): 
Figure 7. Mental space configuration for Princess is eating a goldfish

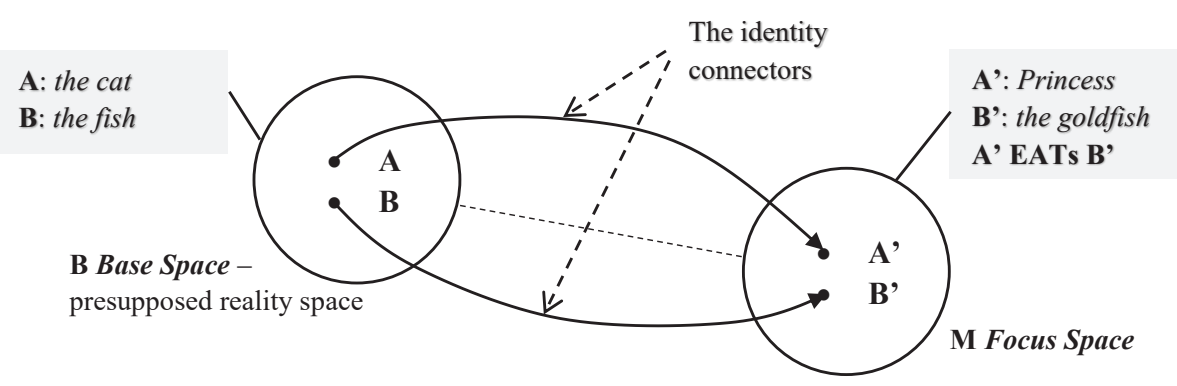

Source: own representation.

Undeniably, the speaker of the above sentence must have assumed that the hearer knows who Princess is because, otherwise, the message would have been formulated in a quite different way. As a result, no reality space seems to be essential, and, in fact, this notion of Fauconnier's is absolutely redundant. Lamb (1999: 199) emphasises that on hearing a message, the receiver needs "to identify the point in the network at which the new information is to be added - in this case, information is to be added to the nection for this cat." The activated subnetwork combines all the nections which indicate the features of this particular cat and cats in general, as well as the linguistic form of the word.

Fauconnier's theory provides a simplified portrayal of mental operations. It emphasises a need for connection building but fails to underline that meaning construction process involves the integration of information from widely-distributed subsystems. Lamb's theory may contribute significantly to the analysis of linguistic examples as it shows an exhaustive representation of a given concept. According to the RNT, a concept triggers the activation of a central coordinating nection which subsumes the whole family of nections which are spread over different modalities and reflect the neural representation of concepts. Typically, a concept evokes the activation of such modality-specific representations as visual, auditory or somatosensory, which are merged with its lexical and phonological representations. Additionally, the concept may trigger other interrelated elements, as well as those nections which represent individual's sensory-motor experience associated with the concept. Thus, the linguistic example provided above is supposed to trigger 
two relational subnetworks for each of the concepts, i.e. one for Princess - the cat and the other one for a goldfish. Additionally, the subnetwork for the verb eat is activated together with its experiential engrams, and lexical and grammatical information about the action of 'eating'. The verb also instigates the creation of a connection between the two nections, i.e. Princess - the cat, and a goldfish, which is essential for the purpose of the current discourse.

Undoubtedly, the assumptions of both theories are not mutually exclusive. To the contrary, the RNT, as well as the CIT, provide valuable information about linguistic processing which, when combined, may illuminate significantly the process of meaning construction. Mental spaces appear to shed light on those parts of the linguistic network which are evoked by the linguistic input. The RNT, in turn, emphasises that each subnetwork subsumes nections which reflect the meaning of a concept and are distributed over different areas of the human brain, and those nections which reveal the form of the word and are localised mainly in the perisylvian cortice of the left hemisphere where the canonical language areas are situated.

\section{The Relational Network Theory and the Conceptual Integration Theory in Slips of the Tongue}

Evans and Green (2006: 401) underline that conceptual blending is " $[\mathrm{c}] \mathrm{en}$ tral to human thought and imagination (...) [and] proved useful in a wide range of disciplines such as mathematics, music theory, religious studies, the study of occult, linguistics, cognitive psychology, social psychology, anthropology." It illuminates cognitive processes and explicates both linguistic and nonlinguistic operations. In fact, integration is an omnipresent process as nearly all human activities involve the juxtaposition of new information or situation against background knowledge and experience. Even the speech generation model itself reveals the binding process which, in fact, operates at various linguistic levels. As the RNT highlights, each linguistic level is subject to tactic patterns which restrict the creation of links between stratal elements. It could thus be presumed that each linguistic level features frames, of which slots are structured according to the inherent tactics, and which determine fillers that can be assigned to these slots. Those skeletal structures are extracted from the cognitive background and zoomed in by Facuonnier and Turner's generic space that provides the basis for on-line meaning construction. Ongoing dis- 
course necessitates either the integration of those frames or their completion or extension. Noteworthy as it is, frames do not respect stratal boundaries, so lower level frames are filled with elements provided by the input from the upper level. Hence, for instance, syntactic frames are completed with lemmas which are structured not only grammatically but also semantically, and morphological frames draw upon the input from the lexemic level.

As Levelt (1991: 321) emphasises these are "[s]peech errors [which] provide ample evidence for the independent availability of word sketches or frames and of the elements that are to fill them. (...) There are frames with positions for morphemes, phonemes or other elements; during speech these frames are filled with candidate elements." Govindje and Dell (2014: 105) also claim that "[1] anguage production models embody this structure/content distinction by using a frame-and-slot mechanism for planning sentences." Linguistic processing thus necessitates the activation of appropriate frames within a generalised tactic pattern. Only those fillers which are congruent with the active slot are bound with the slots of the evoked frame. It may, however, happen that different fillers compete for the same slot. As a result of some internal or external distractions, an erroneous element may be chosen to complete the frame and, a speech error, which results from a fault during the slot-binding process may occur. That is why verbal blunders hardly ever violate phonological or syntactic rules of a given language and typically, the faulty element is either phonologically or semantically related to the target item or exhibits syntagmatic relation with the intended element. Errors are thus supposed to arise during the slot-binding process at one of the linguistic levels which, in turn, comply with the tactics of a particular stratum.

As an example, consider a semo-lexemic anticipation error which was drawn from Jeri Jaeger's Adult Slips Database ${ }^{1}$ which is published online for other researchers to analyse. To provide a clear reference to the source of the blunder Jaeger's description of the error and its context was adopted. The abbreviation AD stands for Adult Database, and the number signifies the position of the error in the database:

1 [online:] http://arts-sciences.buffalo.edu/content/dam/arts-sciences/linguistics/Faculty/Jaeger\%20-\%20AdultData.pdf [23.09.2018]. 
AD-562 When Audrey was little, she had a baby sister named Barbara. (semo-lexemic anticipation - substitute baby sister for babysitter)

CONTEXT: when Audrey was little, she had a babysitter named Barbara. Audrey herself did not have a sister, but Barbara did. Having uttered the sentence, the speaker went on to talk about Barbara's baby sister, whose name was Michelle.

Noteboom (1969: 151) emphasises that "speech errors occur most frequently in those fragments of speech chain on which the attention of the speaker is focused." Thus, the words which the speaker concentrates on the most or which convey the gist of the utterance may receive premature activation. The speaker of the sentence must have known what he wanted to talk about before he started uttering the sentence. As the comment suggests, he wished to remark on Barbara's baby sister and the aforementioned utterance was an introduction to the discourse which was to follow. The two words babysitter and baby sister were probably triggered and were awaiting recruitment in due course. However, owing to their phonological similarity, the word baby sister received a premature activation and replaced the intended element. Braver (2007: 251, 252) notices that "when items simultaneously stored in working memory have to be serially recalled, performance is significantly worse when the items to be maintained are phonologically similar." As a result, when the speaker's attention is somehow diverted from the speech generation process, an erroneous element may win its way to final production, especially when the target element and the source of the error share some parts of their relational subnetwork.

In compliance with Fauconnier and Turner's assumptions, the above example evokes two mental spaces which provide the input for linguistic processing (Fig. 8). One space depicts Audrey's childhood and foregrounds the relation between Audrey and Barbara, and the other input incorporates Barbara and her baby sister Michelle, who was to be the focus of the subsequent talk. By means of the Access Principle (Fauconnier 1994, 1997), Barbara is linked to her counterpart in the other input space and is subsequently projected into the blended space. The blend inherits elements from the first input space but topology structure from the second one, which results in a change of relations between elements. In the blended space, Barbara becomes Audrey's baby sister and Audrey is older than Barbara. The blend portrays a scenar- 
io which is incongruent with actual knowledge but in concord with syntactic requirements. The CIT shows how the integration of linguistic input with the evoked frame is carried out but it does not illuminate linguistic reasons for a verbal slip-up. It is Lamb's theory which explicates linguistic underpinnings for such slips of the tongue. The RNT clarifies that both words baby sister and babysitter share parts of the linguistic network (Fig. 8), and the error word leaked into the external speech plan because attentional control was diverted from the ongoing production process onto the internal draft of the to-be-conveyed message.

\section{Conclusion}

Slips of the tongue are an extremely interesting type of phenomena that betray aspects of linguistic processing. They reflect the malfunctioning of the linguistic encoding process and show that speech generation process involves the integration of linguistic elements into the pre-established knowledge structures which comply with the rules of a given language. The two theories, i.e. the CNT and the RNT, appear to complement each other in the analysis of linguistic examples as they provide an insight into different aspects of linguistic processing. The former brings to light an extremely vital operation - integration, which, in fact, accompanies a great number of linguistic and non-linguistic operations, and the latter shows that language is a stratified system of relations which are subject to internal rules, otherwise called tactic patterns. The main assumptions of the RNT and CIT are summarised in the table below. 
Figure 8. Semo-lexemic anticipation error

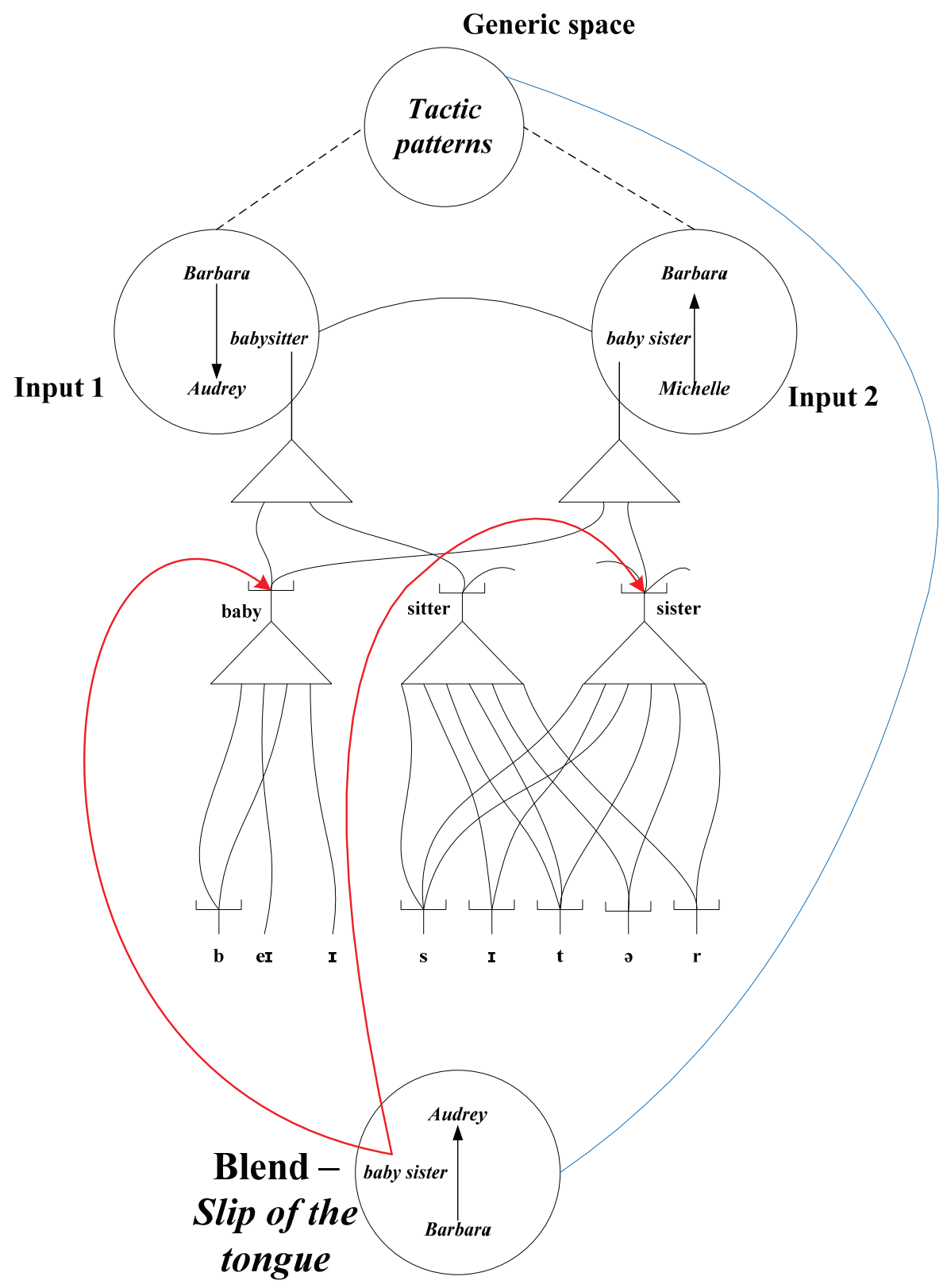

Source: own representation. 
Table 1. A general overview of the RNT and the CIT

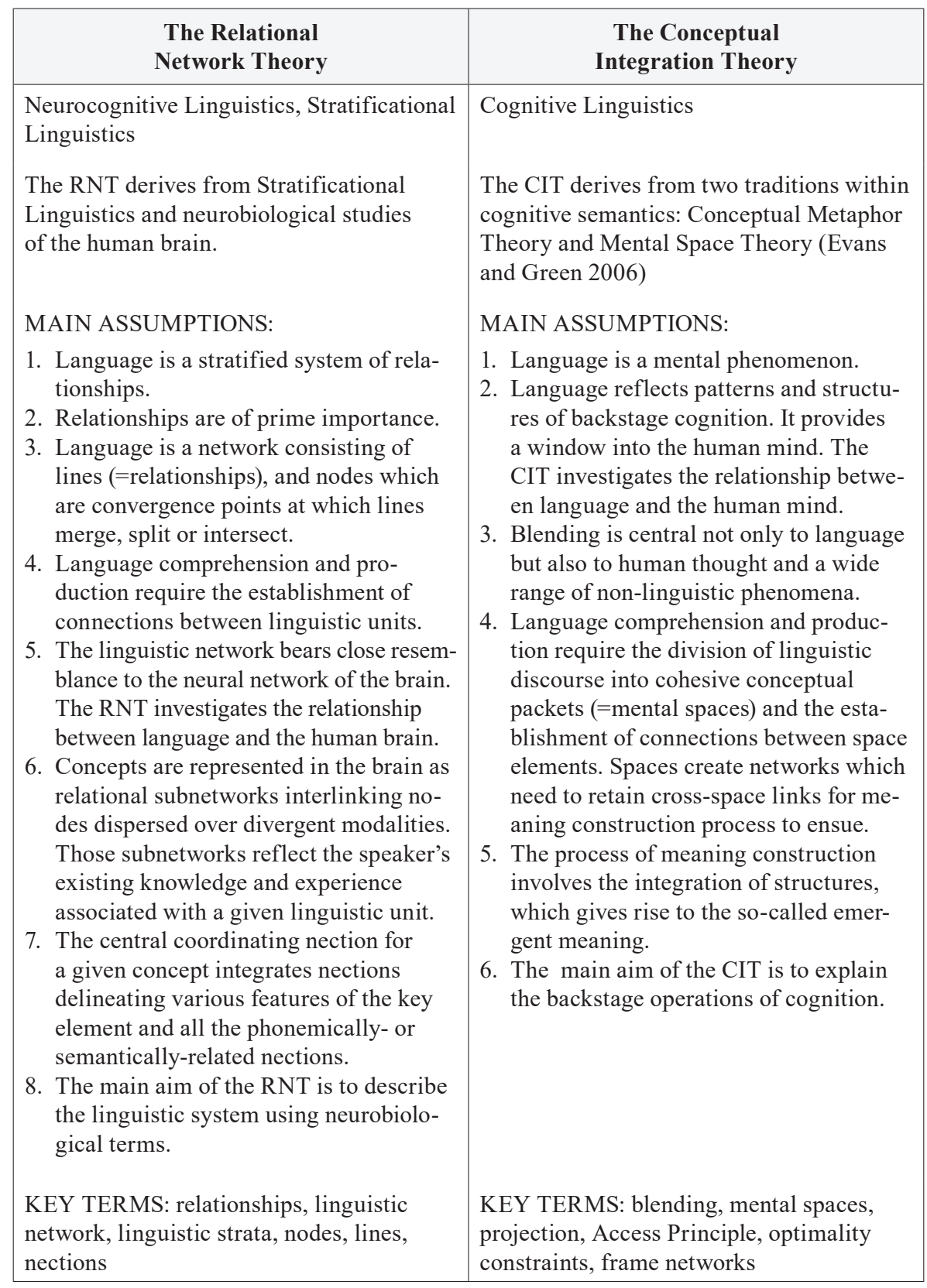

Source: own representation. 
With its neurobiological underpinnings, the RNT illuminates conceptual representations and shows that, apart from vital language areas, other modality-specific regions of the brain are involved in linguistic processing. A mental space thus cannot be said to contain only lexical items but rather parts of the relational network which, as Lamb (1999) claims, the linguistic system appears to be. Lamb's portrayal of the structure of the linguistic system seems to be highly reliable because, as a rule-based system of signs, language does reveal a great many relationships, and all the linguistic elements are somehow interwoven with one another. Consistent with neurobiological findings, the RNT may help to reduce mind-brain dichotomy and facilitate the translation of linguistic theories in neurobiological terms. First, however, it needs to be proved that the RNT is compatible with cognitive approaches to the study of language, as only then will Lamb's assumptions appear to be unimpeachable.

\section{References}

Abeles M., 1991, Corticonics: Neural Circuits of the Cerebral Cortex, Cambridge: Cambridge University Press.

Braver T.S., 2007, Working memory, In: E. E. Smith, S. M. Kossyln (eds.), Cognitive psychology: Mind and brain, pp. 239-279.

Coulson S., 2001, Semantic Leaps: Frame-Shifting and Conceptual Blending in Meaning Construction, New York: Cambridge University Press.

Evans V., Green M., 2006, Cognitive Linguistics: An Introduction, Edinburgh: Edinburgh University Press Ltd.

Fauconnier G., 1994, Mental Spaces: Aspects of Meaning Construction in Natural Language, New York: Cambridge University Press.

FauCONnier G., 1997, Mappings in Thought and Language, New York: Cambridge University Press.

Fauconnier G., Turner M., 1998, Conceptual Integration Networks, Cognitive Science 22(2), pp. 133-187.

Fauconnier G., Turner M., 2002, The Way we Think: Conceptual Blending and the Mind's Hidden Complexities, New York: Basic Books.

Fernandino L., Binder J.R., Desai R.H., Pendl S.L., Humphries C.J., Gross W.L., Conant L.L., Seidenberg M.S., 2016, Concept Representation Reflects Multimodal Abstraction: A Framework for Embodied Semantics, Cerebral Cortex 26, pp. 2018-20134, [online] https://doi.org/10.1093/cercor/bhv020. 
Geeraerts D., Cucyckens H. (eds.), 2007, The Oxford Handbook of Cognitive Linguistics, Oxford: Oxford University Press.

Govindje A., Dell G., 2014, Structure and content in word production: Why it's hard to say dlorm?, In: M.C. Mozer, P. Smolensky, D. Touretzky, J. Elman, A. Weigend (eds.), Proceedings of the 1993 Connectionist Models Summer School, New York: Psychology Press, pp. 105-112.

Lakoff G., Johnson M., 2003, Afterword to Metaphors we Live by, Chicago: The University of Chicago Press.

Lamв S., 1966, Outline of Stratificational Grammar, Washington, D.C.: Georgetown University Press.

Lamb S., 1999, Pathways of the Brain: The Neurocognitive Basis of Language, Philadelphia: John Benjamins Publishing Company.

Lamb S., 2004, Selected Writings of Sydney Lamb: Language and Reality, London: Continuum.

Levelt W.J.M., 1991, Speaking: From Intention to Articulation, Cambridge: The MIT Press.

Lockwood D.G., 1972, Introduction to Stratificational Lingistics, New York: Harcourt Brace Jovanovich, Inc.

Noотевоом S.G., 1969, The tongue slips into patterns, in: V.A. Fromkin (ed.), Speech errors as linguistic evidence, pp. 144-156.

Patterson K., Nestor P., Rogers T.T., 2007, Where do you know what you know? The representation of semantic knowledge in the human brain, Nature Reviews: Neuroscience 8(12), pp. 976-987, [online] http://psycnet.apa.org/doi/10.1038/nrn2277.

Pulvermüller F., 1999, Words in the Brain's Language, Behavioural and Brain Sciences 22, pp. 253-336.

Westerland M., Pylkkänen L., 2017, How Does the Left Anterior Temporal Lobe Contribute to Conceptual Combination? Interdisciplinary Perspectives, In: J.A. Hampton, Y. Winter (eds.), Compositionality and Concepts in Linguistics and Psychology, pp. 269-290, [online] https://doi.org/10.1007/978-3-319-45977-6.

\section{Komplementarność teorii sieci relacyjnych i teorii amalgamatów (streszczenie)}

Celem artykułu jest wykazanie, że Teoria Sieci Relacyjnych Sydneya Lamba (1999) i Teoria Integracji Konceptualnej Fauconniera i Turnera (1998) są komplementarne i mogą wzajemnie się uzupełniać podczas analizy różnorodnych zjawisk językowych. Artykuł przedstawia główne założenia obu teorii oraz opisuje stratyfikacyjny model budowy języka zaproponowany przez Sydneya Lamba. Wg Lamba, język stanowi sieć relacji, która ma wiele cech wspólnych z siecią neuronów znajdu- 
jących się w mózgu człowieka. Fragment takiej sieci powiązań jest aktywowany pod wpływem stymulacji językowej oraz uwydatniony poprzez przestrzenie mentalne. Autorka artykułu podkreśla również, że proces integracji zachodzi na wszystkich płaszczyznach języka i odgrywa ogromną rolę w procesie tworzenia lub interpretacji wypowiedzi, co jest szczególnie widoczne w analizie lapsusów językowych. 
